\title{
Usefulness of desensitization protocol for a carboplatin hypersensitivity reaction during docetaxel-carboplatin therapy for recurrent ovarian cancer: Case report
}

\author{
TADAHIRO SHOJI, ERIKO TAKATORI, YOSHITAKA KAIDO, SEISUKE KUMAGAI, \\ SATOSHI TAKEUCHI, AKIRA YOSHIZAKI and TORU SUGIYAMA \\ Department of Obstetrics and Gynecology, Iwate Medical University School of Medicine, Iwate 020-8505, Japan
}

Received July 28, 2010; Accepted September 20, 2010

DOI: $10.3892 / \mathrm{ol} .2010 .192$

\begin{abstract}
We report a case of recurrent ovarian cancer in which desensitization for a carboplatin hypersensitivity reaction proved useful. The patient was a 65 -year-old woman who presented with a recurrence of stage IIIc ovarian cancer. The initial chemotherapy consisted of 6 courses of paclitaxel and carboplatin. Recurrence in the pelvis, splenic hilum and paraaortic lymph nodes was detected 19 months after the final day of treatment. The patient was treated with docetaxel-carboplatin therapy for the recurrence, but a Grade 3 hypersensitivity reaction to carboplatin was observed during the second course. Carboplatin desensitization was commenced with the third course and 6 courses were completed with no evidence of hypersensitivity reaction. The antitumor effect showed a complete response and the patient has had a disease-free survival thus far. Desensitization for patients diagnosed with a carboplatin hypersensitivity reaction appeared to be a key method of treatment for prolonging the survival time of patients with recurrent ovarian cancer.
\end{abstract}

\section{Introduction}

Platinum preparations are key drugs for the treatment of platinum-sensitive recurrence of ovarian cancer 6 months or more after the previous treatment $(1,2)$. The therapeutic effect of one such drug, carboplatin, is equivalent to that of cisplatin. It is characterized by not requiring infusion loading during administration and by giving rise to adverse events, including nausea and vomiting, that are adequately managed $(3,4)$, and it is used in combination with paclitaxel or docetaxel. However, it was reported that carboplatin hypersensitivity reactions

Correspondence to: Dr Tadahiro Shoji, Department of Obstetrics and Gynecology, Iwate Medical University School of Medicine, 19-1 Uchimaru, Morioka, Iwate 020-8505, Japan

E-mail: tshoji@iwate-med.ac.jp

Key words: ovarian cancer, carboplatin, hypersensitivity reaction, desensitization develop in response to frequent doses and the patient may lapse into a severe reaction. Additionally, the drug may be difficult to use in routine clinical practice (5). It was recently reported that performing desensitization enables the safe administration of carboplatin $(6,7)$.

We report a case of recurrent ovarian cancer in which it was possible to safely resume carboplatin administration following desensitization in a patient who had developed a hypersensitivity reaction to carboplatin during docetaxelcarboplatin therapy (DC therapy).

\section{Case report}

Patient. The patient was a 65-year-old woman. The obstetric history was gravida 4 , para 2 , while her family history was insignificant. Her past medical history consisted of total abdominal hysterectomy for uterine myoma at 47 years of age and partial transverse colectomy for colon cancer at 61 years of age. She had no history of allergy.

History of the present illness. In July 2007, the patient was referred to us from the Department of Surgery of our hospital for a detailed examination due to the discovery of a pelvic mass. As a result of the examination, a pre-operative diagnosis of ovarian cancer was made and an exploratory laparotomy was performed in August 2007. However, carcinomatous peritonitis was discovered and a bilateral uterine adnexectomy was performed. The diagnosis was stage IIIc ovarian cancer and the histological type was poorly differentiated serous papillary adenocarcinoma. Post-operatively, the patient was treated with 6 courses of paclitaxel-carboplatin therapy (TC therapy). No clinical evidence of disease (NED) was noted in January 2008 and the initial treatment was concluded. The patient received follow-up in the outpatient clinic, but in August 2008 a 4-cm mass in the pelvis, a 2-cm mass in the splenic hilum and a para-aortic lymph node enlargement were detected, and a recurrence was diagnosed. The CA125 value at the time was $67.4 \mathrm{U} / \mathrm{ml}$. Since multiple metastases had been detected, chemotherapy was selected as the treatment modality. Moreover, the patient had experienced Grade 2 peripheral neuropathy during the initial TC therapy and, in accordance with the patient's wishes, it was decided 
to treat the recurrence with DC therapy. The first course of the DC therapy (docetaxel $70 \mathrm{mg} / \mathrm{m}^{2}$, carboplatin AUC 6) commenced in the outpatient clinic in September 2009.

Course of the current illness. Adverse events at the completion of the first course consisted of Grade 3 neutropenia, Grade 1 alopecia and Grade 1 peripheral neuropathy.

The second course commenced in October 2009, however, $20 \mathrm{~min}$ following the start of carboplatin administration (when $25 \%$ of the dose had been administered) facial flushing, sweating and chest discomfort were noted. A carboplatin hypersensitivity reaction was diagnosed and the patient was treated with cortisone, famotidine and chlorpheniramine. Respiratory discomfort also developed and, as $\mathrm{SpO}_{2}$ had decreased to $87 \%, 3 \mathrm{l} / \mathrm{min}$ of $\mathrm{O}_{2}$ was administered. The patient later developed generalized eczema and experienced no relief from the symptoms. A Grade 3 allergic reaction was diagnosed and the remainder of the carboplatin dose was not administered.

Based on the CA125 value of $20.7 \mathrm{U} / \mathrm{ml}$ and the Gynecologic Cancer Intergroup criteria at the end of the second course, a partial response was recorded. After obtaining sufficient informed consent from the patient, it was decided to continue DC therapy from the third course onwards. Carboplatin was administered using the desensitization method to overcome the carboplatin hypersensitivity reaction.

The patient was admitted in November and the third course of DC therapy was commenced. Following administration of granisetron $3 \mathrm{mg} /$ body and dexamethasone $8 \mathrm{mg} /$ body, docetaxel $100 \mathrm{mg} /$ body was dissolved in $100 \mathrm{ml}$ of physiological saline solution (PSS) and administered over $60 \mathrm{~min}$. A $0.1-\mathrm{ml}$ volume of carboplatin $600 \mathrm{mg} /$ body dissolved in $100 \mathrm{ml}$ of PSS (used as the standard solution) was removed and after being dissolved in $100 \mathrm{ml}$ of PSS, it was administered over $60 \mathrm{~min}$ via intravenous drip infusion (i.v. drip). Then, $1 \mathrm{ml}$ of the standard solution was removed and after being dissolved in $100 \mathrm{ml}$ of PSS, it was administered by i.v. drip over $60 \mathrm{~min}$. An additional $10 \mathrm{ml}$ of the standard solution was removed and after being dissolved in $100 \mathrm{ml}$ of PSS, it was administered by i.v. drip over $60 \mathrm{~min}$. Finally, the remainder of the stock solution was administered over $60 \mathrm{~min}$ by i.v. drip and this was concluded without any evidence of a hypersensitivity reaction (Table I). The patient was monitored for a number of days, but no serious adverse effects were observed, and she was discharged on day 3 after administration. Treatment was subsequently continued until 6 courses; no hypersensitivity reaction was observed and a complete response of the lesions evaluated was obtained. A state of disease-free survival was confirmed in February 2010.

Follow-up in the outpatient clinic is currently ongoing, but no evidence of recurrence has been detected thus far.

\section{Discussion}

Hypersensitivity reactions are one of the rare adverse events associated with chemotherapy and they consist of acute and chronic reactions (8). For example, hypersensitivity reactions to paclitaxel commonly occur immediately after administration of the drug, known as acute hypersensitivity reactions (9). However, chronic hypersensitivity reactions are also noted. These reactions are said not to occur unless repeated courses
Table I. Desensitization protocol.

\begin{tabular}{lcc}
\hline Step & $\begin{array}{c}\text { Carboplatin equivalent } \\
\text { (concentration) }\end{array}$ & $\begin{array}{c}\text { Administration time } \\
\text { (min) }\end{array}$ \\
\hline 1 & $1 / 1,000$ & 60 \\
2 & $1 / 100$ & 60 \\
3 & $1 / 10$ & 60 \\
4 & $1 / 1$ (standard solution) & 60 \\
\hline
\end{tabular}

Carboplatin $600 \mathrm{mg} /$ body dissolved in $100 \mathrm{ml}$ of physiological saline solution (PSS) was used as the standard solution. Step 1, a $0.1-\mathrm{ml}$ volume of the standard solution was removed, dissolved in $100 \mathrm{ml}$ of PSS and administered via intravenous drip infusion (i.v. drip) over $60 \mathrm{~min}$. Step 2, a 1-ml volume of the standard solution was removed, dissolved in $100 \mathrm{ml}$ of PSS and administered by i.v. drip over $60 \mathrm{~min}$. Step 3, a 10-ml volume of the standard solution was removed, dissolved in $100 \mathrm{ml}$ of PSS and administered by i.v. drip over $60 \mathrm{~min}$. Step 4, the remainder of the standard solution was administered by i.v. drip over $60 \mathrm{~min}$.

of drugs such as carboplatin are administered (10-13). Acute reactions are type I allergic reactions caused by $\operatorname{IgE}$ and, although mast cell involvement has been suggested in chronic reactions, the exact mechanism remains to be elucidated (14). Although such reactions are rare, sufficient caution is crucial due to the possibility of developing serious or fatal anaphylaxis. The incidence of carboplatin hypersensitivity reactions is said to be $12 \%$ (5) and it is claimed that these reactions are most common during the 8 th or 9 th dose $(15,16)$. Shepherd et al found that when the number of doses reached 7 or more, the risk of developing a carboplatin hypersensitivity reaction increased to $27 \%$ (17), but no clear risk factors or effective methods of prediction have been identified thus far (18-20).

Treatment policies following a hypersensitivity reaction are largely divided into resumption of treatment with a platinum drug in combination with another measure or a switch to a non-platinum drug. A high response rate to treatment that includes a platinum drug is anticipated, particularly in platinum-sensitive recurrent ovarian cancer (1). Moreover, platinum-based chemotherapy has been shown to be superior to chemotherapy with non-platinum drugs (2), and it is preferable to perform platinum-based chemotherapy where possible. Generally cited methods of coping with hypersensitivity when carboplatin administration is resumed are: i) pre-medication enhancement methods, by adding a steroid preparation and antihistaminic (14); ii) switching methods, in which a change is made to another platinum drug, such as cisplatin (14); and iii) desensitization $(10,13,18)$, as used in our patient.

Carboplatin was prepared in four different concentrations: $1 / 1,000,1 / 100,1 / 10$ and the standard solution. The patient was admitted and her ECG and oxygen saturation were monitored. The dose of paclitaxel was administered, followed by the carboplatin solutions down to the $1 / 10$ concentration each in order over a 1-h period. The final standard solution was administered over $1.5 \mathrm{~h}$. The carboplatin administration time was $4.5 \mathrm{~h}$, a shorter time period than in earlier reports $(9,12,14)$, and even when the docetaxel administration time was added, administration was possible within $6 \mathrm{~h}$. All of the 
courses down to the 6 th course were administered following patient admission. However, administration also appeared to be possible in the outpatient clinic, if the facility was appropriately equipped.

A study showed that when a carboplatin hypersensitivity reaction occurred prior to the completion of drug administration, it was possible to resume administration by temporarily ceasing administration, and after the patient had recovered, resuming administration by reducing the flow rate to $1 / 4$, then gradually increasing it to $1 / 2$ and finally to the original flow rate $(20)$.

We treated a patient with recurrent ovarian cancer in whom it was possible to resume carboplatin administration safely by desensitization in order to overcome a carboplatin hypersensitivity reaction. If the regimen is altered without selecting desensitization, the drug may not induce a response. Since taxanes and platinum preparations are key drugs for platinum-sensitive cases of recurrent ovarian cancer, even if administration of carboplatin alone becomes impossible, there is concern that fewer drugs may be available for the third and fourth line. Moreover, none of the response rates to the drugs that are used as salvage chemotherapy, with the exception of platinum preparations, are high. Thus, carboplatin desensitization is considered a key method of treatment in order to prolong the patient survival time.

In conclusion, we reported a carboplatin hypersensitivity reaction during DC therapy of recurrent ovarian cancer. Carboplatin desensitization enabled 6 courses to be completed, and disease-free survival was achieved. Carboplatin desensitization is also a useful method of treatment in order to prolong patient survival time in platinum-sensitive cases of recurrent ovarian cancer.

\section{References}

1. Parmar MK, Ledermann JA, Colombo N, du Bois A, Delaloye JF, Kristensen GB, Wheeler S, Swart AM, Qian W, Torri V, Floriani I, Jayson G, Lamont A, Tropé C; ICON and AGO Collaborators: Paclitaxel plus platinum-based chemotherapy versus conventional platinum-based chemotherapy in women with relapsed ovarian cancer: the ICON4/AGO-OVAR-2.2 trial. Lancet 361: 2099-2106, 2003.

2. González-Martin AJ, Calvo E, Bover I, Rubio MJ, Arcusa A, Casado A, Ojeda B, Balañá C, Martínez E, Herrero A, Pardo B, Adrover E, Rifá J, Godes MJ, Moyano A and Cervantes A: Randomized phase II trial of carboplatin versus paclitaxel and carboplatin in platinum-sensitive recurrent advanced ovarian carcinoma: a GEICO (Grupo Espanol de Investigacion en Cancer de Ovario) study. Ann Oncol 16: 749-755, 2005.

3. Ozols RF, Bundy BN, Greer BE, Fowler JM, Clarke-Pearson D, Burger RA, Mannel RS, DeGeest K, Hartenbach EM, Baergen R; Gynecologic Oncology Group: Phase III trial of carboplatin and paclitaxel compared with cisplatin and paclitaxel in patients with optimally resected stage III ovarian cancer: a Gynecologic Oncology Group study. J Clin Oncol 21: 3194-3200, 2003.

4. Du Bois A, Lück HJ, Meier W, Adams HP, Möbus V, Costa S, Bauknecht T, Richter B, Warm M, Schröder W, Olbricht S, Nitz U, Jackisch C, Emons G, Wagner U, Kuhn W, Pfisterer J; Arbeitsgemeinschaft Gynäkologische Onkologie Ovarian Cancer Study Group: A randomized clinical trial of cisplatin/ paclitaxel versus carboplatin/paclitaxel as first-line treatment of ovarian cancer. J Natl Cancer Inst 95: 1320-1329, 2003.
5. Markman M, Kennedy A, Webster K, Elson P, Peterson G, Kulp B and Belinson J: Clinical features of hypersensitivity reactions to carboplatin. J Clin Oncol 17: 1141, 1999.

6. Rose PG, Fusco N, Smrekar M, Mossbruger K and Rodriguez M: Successful administration of carboplatin in patients with clinically documented carboplatin hypersensitivity. Gynecol Oncol 89: 429-433, 2003.

7. Confino-Cohen R, Fishman A, Altaras M and Goldberg A: Successful carboplatin desensitization in patients with proven carboplatin allergy. Cancer 104: 640-643, 2005.

8. Castells MC, Tennant NM, Sloane DE, Hsu FI, Barrett NA, Hong DI, Laidlaw TM, Legere HJ, Nallamshetty SN, Palis RI, Rao JJ, Berlin ST, Campos SM and Matulonis UA: Hypersensitivity reactions to chemotherapy: outcomes and safety of rapid desensitization in 413 cases. J Allergy Clin Immunol 122: 574-580, 2008

9. Markman M, Kennedy A, Webster K, Elson P, Peterson G, Kulp B and Belinson J: Paclitaxel-associated hypersensitivity reactions: experience of the gynecologic oncology program of the Cleveland Clinic Cancer Center. J Clin Oncol 18: 102-105, 2000.

10. Lee CW, Matulonis UA and Castells MC: Rapid inpatient/ outpatient desensitization for chemotherapy hypersensitivity: standard protocol effective in 57 patients for 255 courses. Gynecol Oncol 99: 393-399, 2005.

11. McElroy TM, Gruenigen VE and Waggoner SE: A case of prolonged carboplatin therapy in a patient with carboplatin hypersensitivity. Gynecol Oncol 91: 435-437, 2003.

12. Navo M, Kunthur A, Badell ML, Coffer LW II, Markman M, Brown J and Smith JA: Evaluation of the incidence of carboplatin hypersensitivity reactions in cancer patients. Gynecol Oncol 103: 608-613, 2006.

13. Lee CW, Matulonis UA and Castells MC: Carboplatin hypersensitivity: a 6-h 12-step protocol effective in 35 desensitizations in patients with malignancies and mast cell/IgE-mediated reactions. Gynecol Oncol 95: 370-376, 2004.

14. Lenz HJ: Management and preparedness for infusion and hypersensitivity reactions. Oncologist 12: 601-609, 2007.

15. Markman M, Hsieh F, Zanotti K, Webster K, Peterson G, Kulp B, Spicel A and Belinson J: Initial experience with a novel desensitization strategy for carboplatin-associated hypersensitivity reactions: carboplatin-hypersensitivity reactions. J Cancer Res Clin Oncol 130: 25-28, 2004

16. Watanebe $\mathrm{Y}$, Nakai $\mathrm{H}$, Ueda $\mathrm{H}$, Nozaki $\mathrm{K}$ and Hoshiai $\mathrm{H}$ : Carboplatin hypersensitivity induced by low-dose paclitaxel/ carboplatin in multiple platinum-treated patients with recurrent ovarian cancer. Int J Gynecol Cancer 15: 224-227, 2005.

17. Shepherd GM: Hypersensitivity reaction to chemotherapeutic drugs. Clin Rev Allergy Immunol 24: 253-262, 2003.

18. Schwartz JR, Bandera C, Bradley A, Brard L, Legare R, Granai CO and Dizon DS: Dose the platinum-free interval predict the incidence or severity of hypersensitivity reactions to carboplatin? The experience from Women and Infants' Hospital. Gynecol Oncol 105: 81-83, 2007.

19. McAlpine JN, Kelly MG, O'Malley DM, Azodi M, Coombe K, Schwartz PE and Rutherford TJ: Atypical presentations of carboplatin hypersensitivity reactions: characterization and management in patients with gynecologic malignancies. Gynecol Oncol 103: 288-292, 2006.

20. Markman M: The dilemma of carboplatin-associated hypersensitivity reactions in ovarian cancer management. Gynecol Oncol 107: 163-165, 2007. 